\title{
Digital acrometastasis as presentation of pulmonary adenocarcinoma
}

\begin{abstract}
Bone metastasis with specific involvement of the bones of the hand constitute an event rarely described in the literature. The aetiology is almost exclusive to primary tumours of the lung, with an incidence of 1/500 of all pulmonary lesions that spread to the bone. The diagnosis is extremely challenging, either through the subtle clinic or the mimicry of other entities. The approach to this type of injury is imminently palliative, with the objectives of pain relief and preservation of function. The authors present the case of a patient diagnosed with a proximal phalanx metastases of the thumb as a manifestation of an advanced stage adenocarcinoma of the lung.
\end{abstract}

Keywords: acrometastasis, pulmonary adenocarcinoma, bone metastases of the hand
Volume 10 Issue 3 - 2018

\author{
André Lopes Vasques, Filipa Gonçalves \\ Pereira, Francisco Brito, António Maia de \\ Oliveira \\ 'Médico Interno do Internato Complementar de Ortopedia \\ e Traumatologia, Serviço de Ortopedia e Traumatologia do \\ Hospital José Joaquim Fernandes - ULSBA, Portugal \\ ${ }^{2}$ Médica Interna do Internato Complementar de Ortopedia \\ e Traumatologia, Serviço de Ortopedia e Traumatologia do \\ Hospital José Joaquim Fernandes - ULSBA, Portugal \\ ${ }^{3}$ Médico Interno do Internato Complementar de Ortopedia \\ e Traumatologia, Serviço de Ortopedia e Traumatologia do \\ Hospital José Joaquim Fernandes - ULSBA, Portugal \\ ${ }^{4}$ Assistente Graduado de Ortopedia e Traumatologia, Serviço de \\ Ortopedia e Traumatologia do Hospital José Joaquim Fernandes \\ - ULSBA, Portugal
}

Correspondence: André Carrilho Lima Lopes Vasques, Rua Infante D. Henrique $n^{\circ}$ 19,7800-318 Beja

Tel 00351918352239, Email alopesvasques@gmail.com

Received: May 01, 2018 | Published: May 18, 2018

\section{Introduction}

Bone metastasis occurs in approximately $30 \%$ of all neoplastic disease; ${ }^{1}$ however, specific bone involvement of the hand is an event rarely described in the literature, occurring in only $0.007-0.2 \%$ of all tumours that metastasize. ${ }^{2}$ The aetiology of the acrometastasis (digital metastases) is almost exclusively of the primary tumours of the lung, being a rare event in these, with an incidence of $1 / 500$ of all pulmonary lesions that are disseminated to the bone. ${ }^{3}$ The diagnosis is extremely difficult, either by the subtle clinic or the mimicry of other entities. Rarely do they appear as an initial manifestation of oncological pathology, but when they happen they generally translate a late stage of the disease and provide a reserved prognosis. The approach to this type of injury is imminently palliative, with the objectives of pain relief and preservation of function. ${ }^{4}$

The authors present the case of a patient with a metastatic lesion of the proximal phalanx of the first finger of the hand as a manifestation of an advanced stage adenocarcinoma of the lung.

\section{Case report}

We present a case of a 76-year-old male patient, retired (former worker in copper mines), with a known personal history of hypertension, type II diabetes mellitus and smoker (25 UPY). He was admitted to the Emergency Department with asthenia, anorexia and weight loss of approximately $10 \mathrm{~kg}$ in the last 2 months, associated with periods of temporal disorientation. The initial examination revealed a decrease in the vesicular murmur in the lower half of the left hemithorax, which is why a simple $\mathrm{x}$-ray $(\mathrm{Rx})$ of the thorax was performed, where the presence of a left peri-hilar heterogeneous hypodensity was observed. Considering the findings, a computed tomography $(\mathrm{CT})$ was performed, which highlighted the presence of neoplastic lung lesions involving the left upper lobe and lingula, upper pulmonary vein incarceration, and metastatic dissemination to the contralateral lung. The presence of multiple metastatic lesions was observed, namely in the right humeral neck and D6 vertebral body. Bone Contigraphy was also performed, which showed hyperfixation on the frontal bone, the 4th, 6th, 7th, 8th and 9th right costal arches and vertebral body of D6. During the hospitalization period, due to low energy trauma, when he released a button, he started complaining of pain and edema of the 1st finger of the left hand, associated with painful incapacity in the mobilization of the interphalangeal joint of the same finger, requiring collaboration by Orthopedics. The objective examination revealed edema, flushing and interphalangeal crackling of the first ray of the left hand. He performed a simple $\mathrm{x}$-ray of the hand, which showed a supra-condylar fracture of the proximal phalanx of the 1st finger of the left hand (Figure 1) (Figure 2), and CT of the hand, confirming marked osteolysis and periosteal irregularity (Figure 3). Taking into account the persistence of pain complaints and the type of fracture, the patient was submitted to surgery, with direct approach to the focus of the lesion, collection of material for anatomopathological examination, curettage and cement fixation (Figures 4) (Figure 5), with significant clinical improvement. He was followed up in consultation with Orthopedics, having been discharged at 6 months without any painful complaints at the fracture site. He also maintained a multidisciplinary oncological follow-up, with lung lesion biopsy positive for moderately differentiated lung adenocarcinoma. 


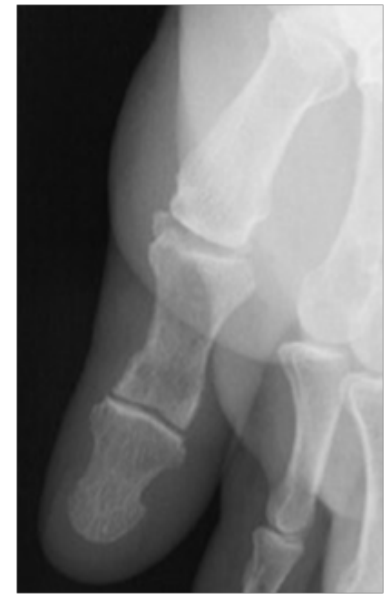

Figure I Antero-posterior view of the first finger.

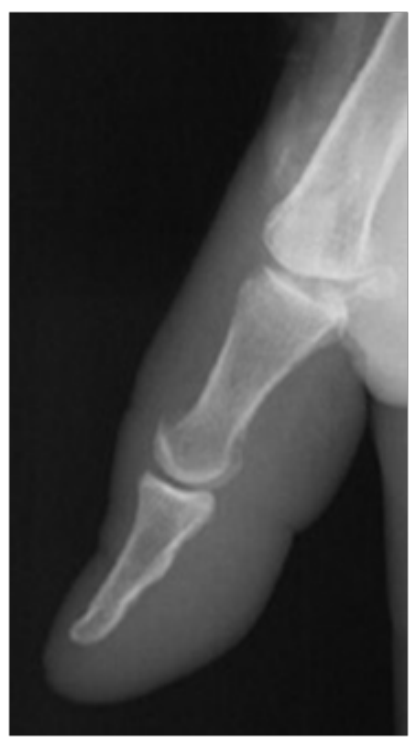

Figure 2 Side view of the first finger.

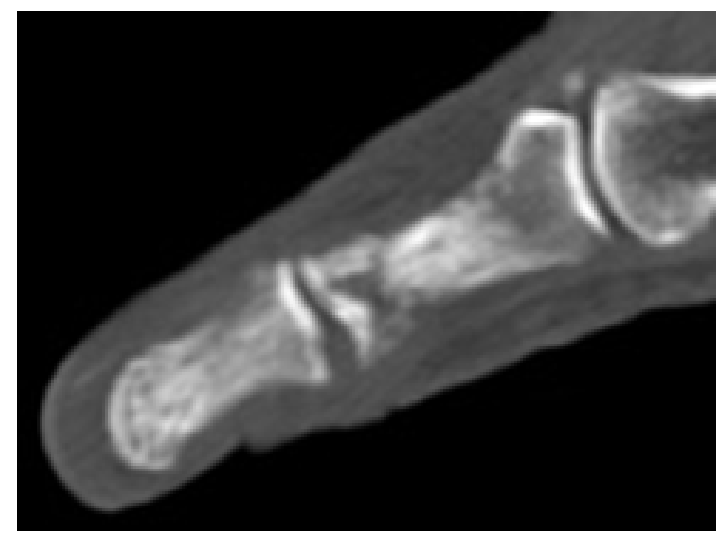

Figure $3 \mathrm{CT}$ scan of the first finger.

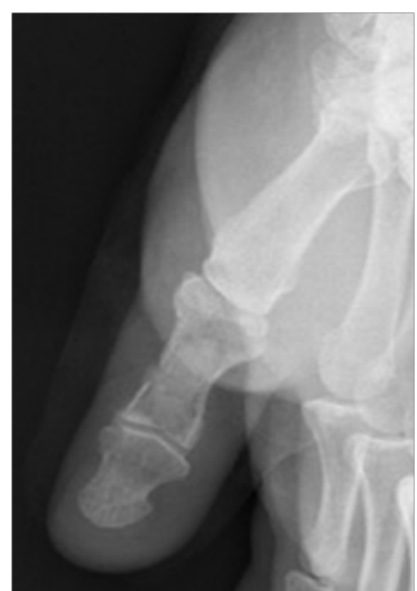

Figure 4 Post-operative antero-posterior view of the first finger.

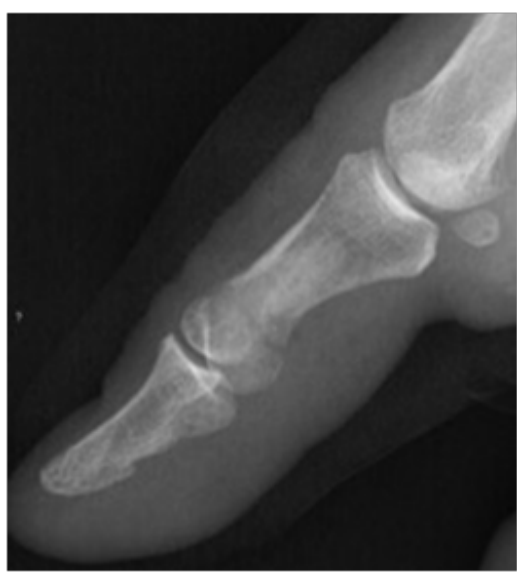

Figure 5 Post-operative side view of the first finger.

\section{Discussion}

The vast majority of tumoral lesions of the hand are benign, usually comprising ganglia, giant cell tumours and lipomas. ${ }^{5}$ Of all neoplastic lesions of the hand with bone involvement, only 1-2\% are malignant. Within these, the presence of secondary lesion, that is, of bone metastases, is even rarer, corresponding to approximately $0.0016-0.5 \%$ of these cases. Acrometastasis are defined as metastatic lesions of the extremities. According to the indexed literature, its presence is about 3 to 4 times more frequent in the upper limbs than in the lower limbs. ${ }^{1}$ The first clinical description of the presence of hand acrometastasis dates back to Handley in $1906 .{ }^{6}$ Several cases have been described since then, mostly on the form of case reports, given their rarity, with an apparent predominance in males.

Whereas acrometastasis of lung neoplasms are rare, their finding as a primary manifestation of the disease is even less frequent (about $10 \%$ of cases). The most frequent primary site of this type of lesion is the lung, corresponding to approximately $40 \%$ of the cases. Following are the kidney $(13 \%)$, breast $(11 \%)$ and gastrointestinal tract. The distal phalanges tend to be more affected, followed by the metacarpal and, finally, the proximal phalanges.

The mechanism of metastasis of this type of lesion is not confirmed, however, it appears to be hematogenic in that malignant 
pulmonary neoplasms have access to the peripheral arterial system or, when associated with traumatic mechanisms, by increased blood supply to the region and release of chemotactic factors..$^{8-10}$

The correct diagnosis of the presence of hand acrometastasis is fundamental, since it can be the initial manifestation of occult neoplasia, and the ease with which the symptoms mimic other benign entities ${ }^{(1)}$. Its radiographic translation is usually that of a lytic lesion with cortical disruption or poorly defined margins, ${ }^{7}$ always requiring a complementary analytical evaluation in case of suspicion. Open lesion biopsy remains the gold standard for obtaining a satisfactory amount of tissue for analysis, and is always complemented by a complete staging study by CT and Bone Scintigraphy. Of equal importance is the multidisciplinary involvement for patient follow-up and therapeutic decision.

The diagnosis of acrometastasis as an initial manifestation of oncological pathology is very rare, but when this happens, it usually means a late stage of the disease, with a poor prognosis and a median survival of 3 to 6 months. ${ }^{3}$ Given this fact, its approach tends to be mainly palliative, focused on the relief of pain and return of normal function. ${ }^{4,8,9}$

The authors believe in the importance of publicizing this type of cases, to alert clinicians to their presence, as well as maintaining a high alert level for their presence.

\section{Acknowledgements}

None.

\section{Conflict of interest}

Authors declare there is no conflict in publishing the article.

\section{References}

1. Healey JH, Turnbull AD, Miedema B, et al. Acrometastases: A Study of Twenty-nine Patients with Osseous Involvement of the Hands and Feet. $J$ Bone Joint Surg Am. 1986;68(5):743-6.

2. Ozcanli H, H Ibrahim Ozdemir, Alpay Merter Ozenci, et al. Metastatic tumors of the hand in three cases. Acta Orthop Traumatol Turc. 2005;9(5):445-448.

3. Akjouj S, El Kettani N, Semlali S, et al. A Thumb Acrometastasis Revealing Lung Adenocarcinoma: A Case Report and Review. J Clin Case Rep. 2013;25(2):106-8.

4. A Jenzer, N Badur, E Vögelin. Composite Bone Cement Arthrodesis In Acrometastasis Of The Proximal Phalanx Of The Hand - A Case Report. The Internet Journal of Orthopedic Surgery. 2011;19(1);1-6.

5. Puhaindran ME, Athanasian EA. Malignant and Metastatic Tumors of the Hand. J Hand Surg. 2010;35A:1895-1900.

6. Bricout PB. Acrometastases. J Natl Med Assoc. 1981;73(4):325-9.

7. Charles S Hsu, Vincent R Hentz, Jeffrey Yao. Tumours of the hand. Lancet Oncol. 2007;8:157-66.

8. Long LS, Brickner L, Helfend L, et al. Lung Cancer Presenting as Acrometastasis to the Finger: A Case Report. Case Rep Med. 2010;2010:234289.

9. Embley MA, Goody RB, Mughrabi M. Occult lung malignancy presenting with finger pain: a case report. J Med Case Rep. 2008;2:364.

10. Mattacheo A, Lucilli N, Palacios A. Acrometastasis Due to Lung Cancer. A Case Presentation. Arch Bronconeumol. 2010;46(5):278-283. 